\title{
The Role of Liquid Fuels Channel Configuration on the Combustion inside Cylindrical Mesoscale Combustor
}

\author{
Achmad Fauzan Hery Soegiharto, ${ }^{1,2}$ I. N. G. Wardana, ${ }^{2}$ \\ Lilis Yuliati, ${ }^{2}$ and Mega Nursasongko ${ }^{2}$ \\ ${ }^{1}$ University of Muhammadiyah Malang, Jalan Raya Tlogomas 246, Malang 65144, Indonesia \\ ${ }^{2}$ University of Brawijaya, Malang, Indonesia \\ Correspondence should be addressed to Achmad Fauzan Hery Soegiharto; fauzanmt@umm.ac.id
}

Received 26 January 2017; Revised 11 May 2017; Accepted 24 May 2017; Published 9 August 2017

Academic Editor: Kazunori Kuwana

Copyright (C) 2017 Achmad Fauzan Hery Soegiharto et al. This is an open access article distributed under the Creative Commons Attribution License, which permits unrestricted use, distribution, and reproduction in any medium, provided the original work is properly cited.

\begin{abstract}
This research intended to investigate combustion of liquid fuel in $3.5 \mathrm{~mm}$ inner diameter quartz glass tube mesocombustor, based on liquid film evaporation by using heat recirculation. The mesocombustor has a copper section for heating and evaporating the liquid fuel. In mesocombustor type A, the fuel was glided through the narrow canal in the copper wall while the air was glided through the axial of combustor. The flame could only be successfully stabilized in high-ratio equivalent ranging from $\phi=1.1$ to $\phi=1.6$, due to the gap without combustion reaction caused by high air-fuel mixture over the limits of flame stability. Mesocombustor type $B$, which has annulus-shaped canal, could shift the flame stability from $\phi=0.8$ to $\phi=1.2$; however, it also narrowed the limits of flame stability due to the wall cooling. In mesocombustor type $\mathrm{C}$, both liquid fuel and air were glided through the annulusshaped canal in the copper wall to fix the fuel evaporation and air mixture. The flame of type $\mathrm{C}$ was successfully stabilized, from $\phi=0.73$ to $\phi=1.48$ wider than types $\mathrm{A}$ and $\mathrm{B}$. The flame of type $\mathrm{C}$ mesocombustor is circle-shaped and fitted to cross section of mesocombustor, but it still has thin gap without any flames due to thermal quenching by the wall.
\end{abstract}

\section{Introduction}

Micropower generator is a small scale portable power generator projected as the battery replacement for power supply in the future portable electronic instruments. Micro/mesoscale combustor is an important component in micropower generator (MPG) functioning to convert chemical fuel energy into heat, which will subsequently be changed into electrical energy in an energy converter module. Micro/mesoscale combustor with a stable combustion and a high rate of heat generation is an absolute component required to realize a high energy density micropower generator. As the key component in MPG, micro/mesoscale combustor has a major issue on the flame stability, especially in the high rate of reactants. The flame instability is mainly caused by high heat loss related to high surface to volume ratio and short fuel residence time which lead to Damkohler number less than unity and uncomplete reaction [1-3].
Many researches are conducted to improve the stability of combustion in micro/mesoscale combustor. The external heater is used in the micro/mesoscale combustor to solve the heat losses problems [4]. Combustor geometry with backward-facing step is used to improve the fuel-air mixing and prolong the fuel residence inside the combustor [5]. Swiss-roll combustor is developed to recirculate the heat from burned product to unburn reactant; results reactant preheating and burning velocity lead to more stable combustion [6]. A catalyst has been used to stabilize the flame inside microcombustor [7]. In these researches, gas fuel which is easy to mix with air into homogenous mixture and burn quickly in a short time is mostly used in the micro/mesoscale combustor. However, gas fuels are not practical for micropower generation, because its storage requires heavy high pressure vessel.

The best fuels for micro/mesoscale combustor are liquid fuels due to their easy handling and storing in a small 


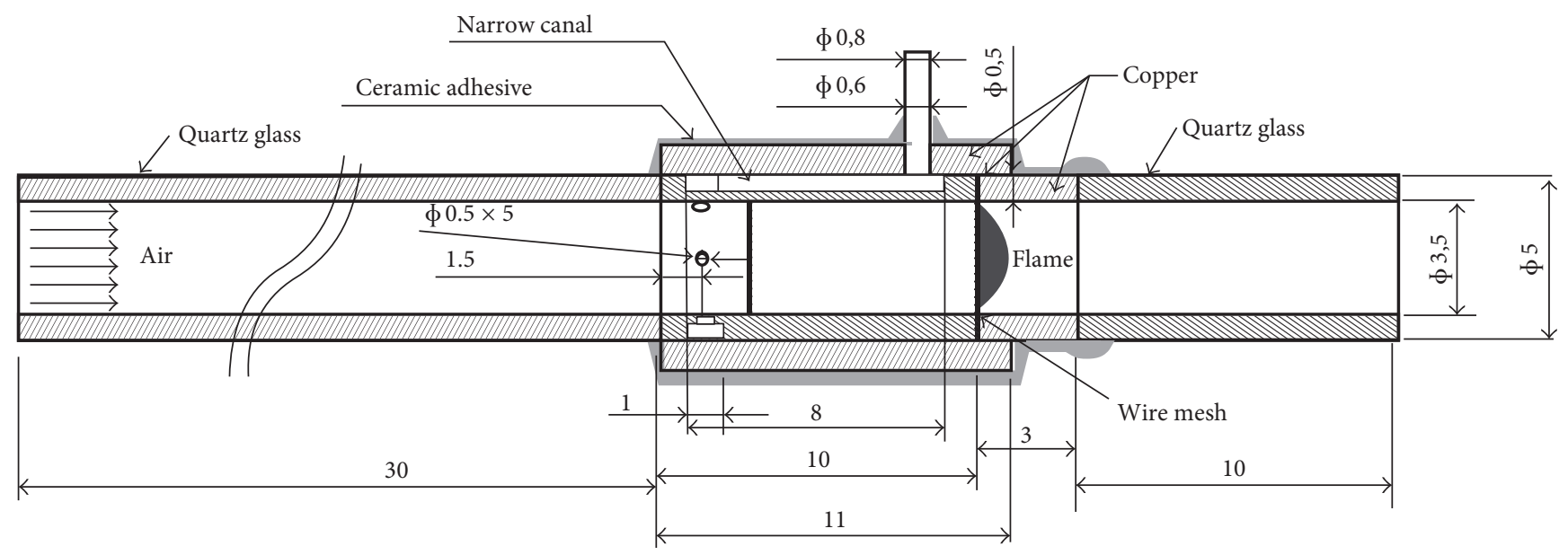

Figure 1: Mesocombustor type A.

container, as well as their safety factor and easy transportation. However, this fuel has more challenge in the micro/ mesoscale combustion, related to its evaporation, mixing with air, and combustion in a very short time. There are some methods to improve the liquid fuel combustion stability in micro/mesoscale combustor, such as catalyst utilization, external heating [8], electrospray atomization $[9,10]$, heatrecirculating burners [11], and liquid film evaporation [2]. The principal of liquid film evaporation is vaporization of thin fuel layer on a hot surface, such as combustor wall. This thin liquid film could quickly absorb the heat from the hot surface and then evaporate. This method offers a better heat transfer compared to spray/droplet methods. The implementation of this liquid film evaporation in micro/mesoscale combustor can be seen in various types of Swiss-roll combustor. Swiss-roll combustor with exhaust gas and liquid fuels which coincided with and were restricted by the wall could highly stabilize the methanol flame [2]. Other Swiss-roll combustions are used for the kerosene, oxygen, and hydrogen. The flame could be stabilized with the thermal efficiency over $90 \%$ [11].

The configuration of Swiss-roll type microcombustor seems to be complex; therefore, the simplification in this combustor type emerges by using $3.5 \mathrm{~mm}$ diameter quartz glass tube. A wire mesh is inserted inside the combustor which has a function as droplet collector and evaporator and flame holder and assists the heat recirculation from the flame to unburn reactant $[12,13]$. The liquid fuel used in this research is the mixture of $30: 70$ percent ethanol-nheptane. The flame could be stabilized without catalyst and external heating. The double inserted wire mesh in a similar combustor could empirically improve the flame stability by separation of droplet collector and evaporator at the first mesh and flame holder at the second mesh $[9,13]$. However, these researches used electrospray method to supply liquid fuel to the combustor. This method needs more equipment and a little energy on the order of $10^{-3}$ watts for atomization process, which produce more complex systems. Therefore, a simple and compact combustor configuration is desirable.

This research aimed to realize a stable flame inside a mesocombustor operating with a liquid fuel based on liquid film evaporation. The liquid film is evaporated by heat recirculation on the copper tube section which has some channel configuration. It demonstrates the stable combustion of hexane inside a narrow glass tube with an inner diameter of $3.5 \mathrm{~mm}$. The combustion characteristics were represented through the flame visualization, flammability limits, and flame temperature. In the next section, combustor in this research is named as mesocombustor, corresponding to its inner diameter which is larger than quenching distance.

\section{Method}

This research used three types of mesocombustor with tubes inner diameter of $3.5 \mathrm{~mm}$. Each mesocombustor was constructed from a quartz glass-copper-quartz glass tube adhered with ceramic adhesive (Ceramabond 569, Aremco Products Inc.). Each mesocombustor has a copper section surrounding the flame. The copper section of each mesocombustor is insulated with layer of the ceramic adhesive. The first mesocombustor (Figure 1), called combustor type A, had a narrow canal along the copper wall that was used to inject the liquid fuels. This narrow canal had a depth, width, and length, respectively, of $0.5 \mathrm{~mm}, 2 \mathrm{~mm}$, and $5 \mathrm{~mm}$ connected to the circular canal surrounding the combustor. There were 5 inlet holes for the fuel vapor on the circular canal. The second combustor (Figure 2) chamber, called combustor type B, had an annulus-shaped combustion canal along the copper wall and 5 inlet fine holes for the fuel vapor into the combustion chamber. The air was flowed to the combustor types A and $B$ from the upstream direction of mesocombustor. In these two combustor types, the fuel vapor and air were mixed inside the combustors. Combustor type $\mathrm{C}$ (Figure 3 ) was similar to type $\mathrm{B}$, having an annulus-shaped combustion canal along the copper wall surrounding the mesocombustor. In type $C$, however, the air was not flowed from the upstream canal to the mesocombustor; instead, it was flowed to the annulusshaped canal as the liquid combustion and therefore the air and fuels could be mixed inside the annulus canal before entering into the combustion chamber. 


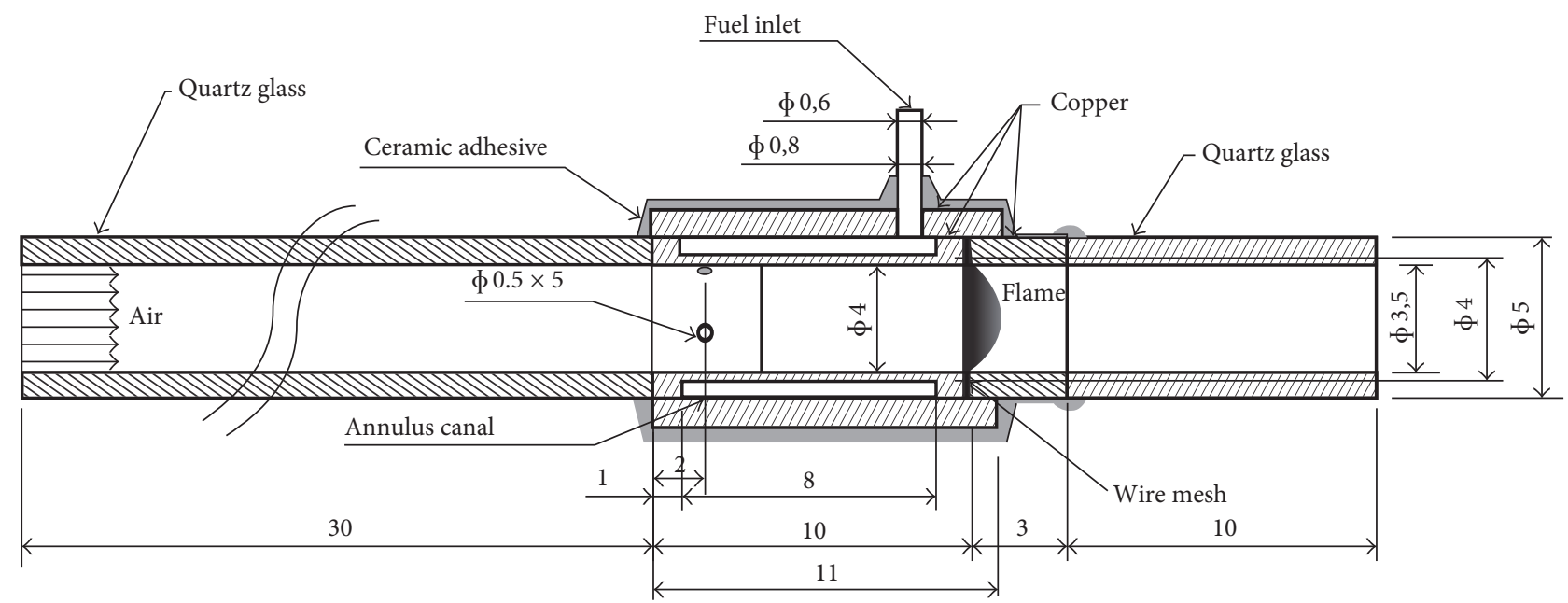

Figure 2: Mesocombustor type B.

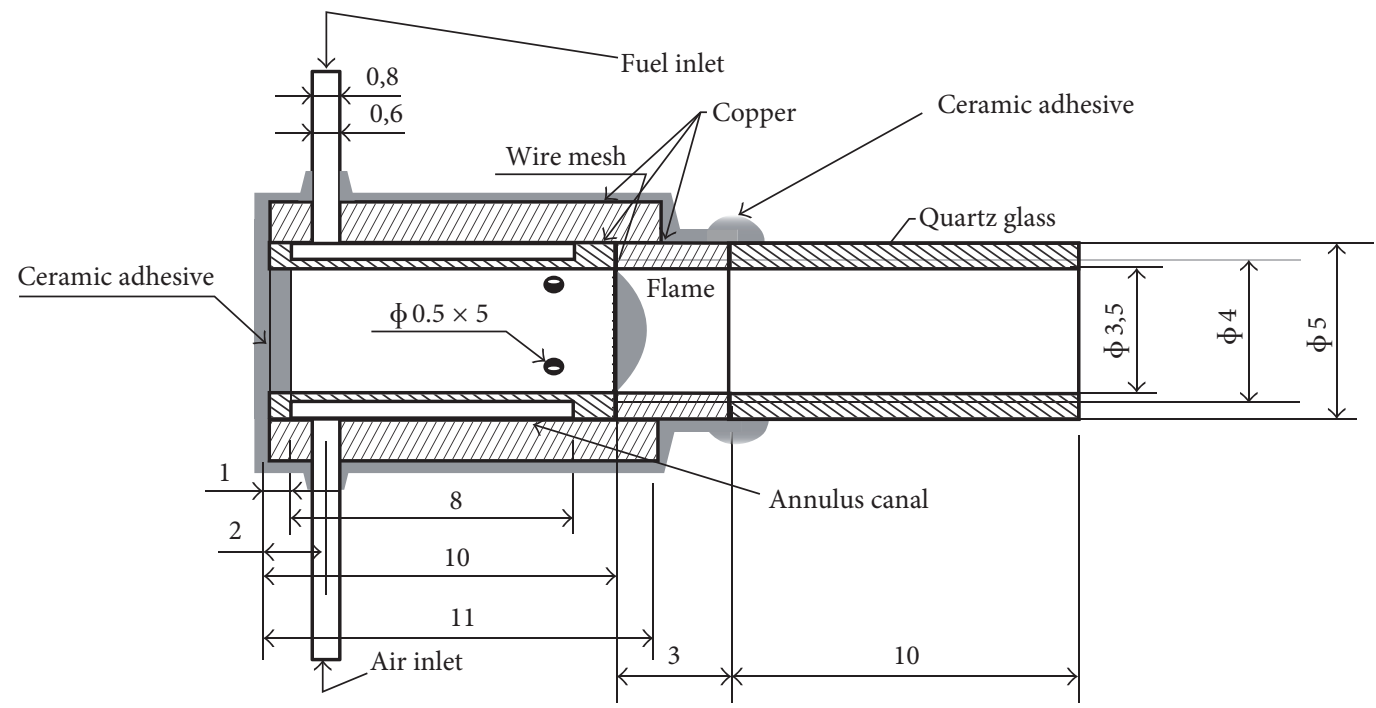

Figure 3: Mesocombustor type C.

In each mesocombustor, the stainless mesh was inserted to improve the air-fuel mixing and as a flame holder. Figures 1-3 illustrate the mesocombustor types A, B, and C.

Mesocombustor was set in the research installation as illustrated in Figure 4. This research used hexane $\left(\mathrm{C}_{6} \mathrm{H}_{14}\right)$ as the liquid fuel and ambient air as an oxidant. The flow rate of hexane volume was controlled by using a syringe pump (NE 1000, New Era). The fuel was injected to the combustor through the fuel inlet, then heated, and evaporated inside the narrow canal or the annulus canal in the copper wall. Subsequently, it flowed to the combustion chamber through the inlet holes of fuel vapor. The air was supplied from compressor tank. The flow rate was adjusted by using flow control (Kofloc), with flow rate ranging from 50 to $500 \mathrm{~mL} /$ minutes. The mixture of fuel vapor and air was ignited at the end of mesocombustor using a torch. The fuel and air flow rate were varied from minimum to maximum value, in which the flame could be stabilized inside the combustion chamber.

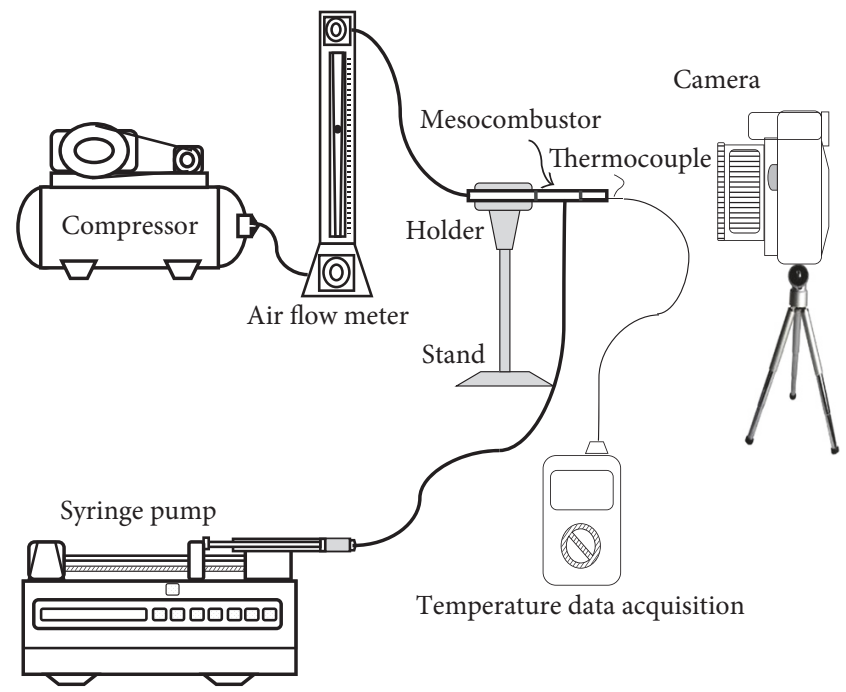

FIGURE 4: Research installation. 


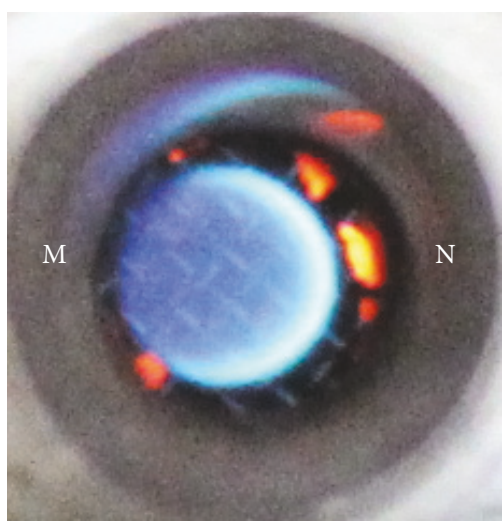

$\phi=1.25$

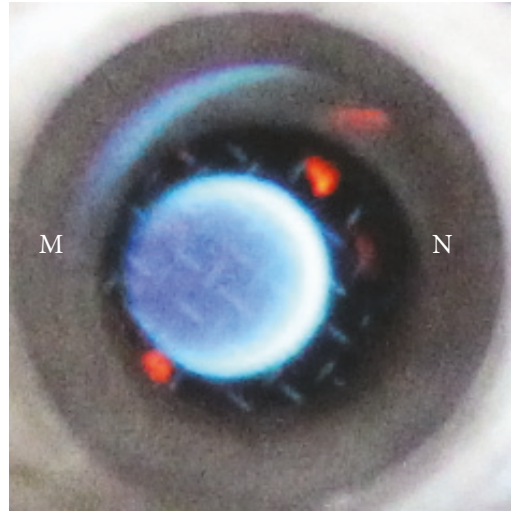

$\phi=1.3745$

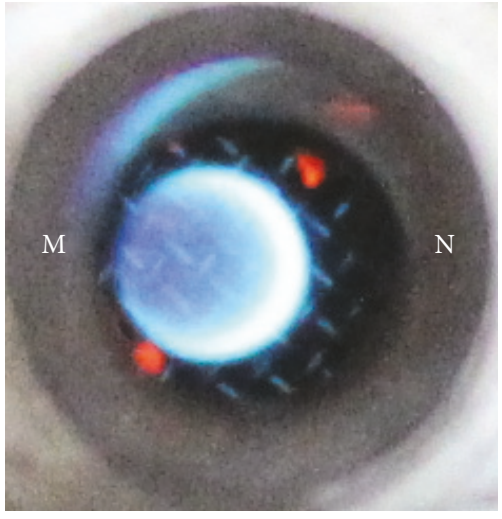

$\phi=1.5$

FIGURE 5: Flame visualization inside mesocombustor type A.

Each flame of the fuel-air ratio was observed within 5 minutes. To ensure flame stability, several flames from the fuel-air ratio are observed in 60 minutes. The observational data are presented in form of flame stability curve of equivalent ratio versus flow velocity. The flame visualization was done by using camera D5200 Nikon. The visualization was taken from front side/downstream flame. The data collection of flame visualization was done at multiple flow velocity and equivalent ratios.

\section{Results and Discussion}

The flame was successfully stabilized inside mesocombustors type $\mathrm{A}$, type $\mathrm{B}$, and type $\mathrm{C}$ using heat recirculation and liquid film evaporation on the copper section, without external heating, catalysts, or additional equipment for atomization. The external heating was merely conducted in the initial process using a torch for ignited flame. Since the flame stabilized inside the combustor near flame holder, the torch was removed from the mesocombustor and the flame kept stable inside the combustor.

Figure 5 illustrates the flame visualization inside mesocombustor type A at reactant velocity of $25.75 \mathrm{~cm} / \mathrm{s}$. The luminosity of the flame was increased with equivalence ratio, while reactant velocity was kept constant. The reaction zone of combustion (flame) was longer due to the decreasing combustion velocity in the fuel rich mixture. The flame seen is thicker and brighter from the front side; on the contrary, the flame color becomes dark blue in fuel lean mixture, at lower equivalence ratio. It can be concluded that combustion of fuel rich mixture has brighter luminosity than fuel lean mixture.

Furthermore, Figure 5 shows that mesocombustor type A had a flame with a circular cross section; however it has nonhomogeneous flame color and asymmetry flame position. The heterogeneity of flame color and asymmetrical flame location possibly are caused by nonuniform reactant distribution on the combustor cross section as shown in Figure 6. This section describes the fuel distribution and flame visualization inside combustor type A. To facilitate discussion, one side of the flame was marked by $\mathrm{M}$ and another side was marked by $\mathrm{N}$ as illustrated in Figure 5. The flame color at the $\mathrm{M}$

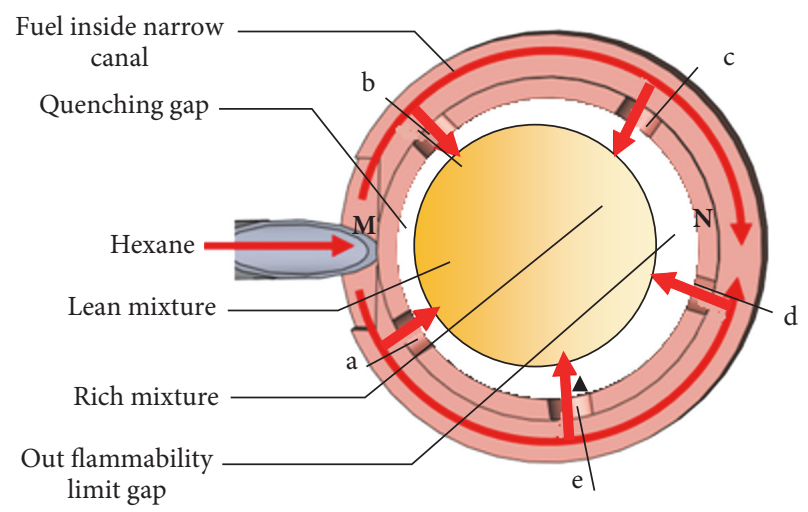

FIGURE 6: Fuel flow in the circular canal inside mesocombustor wall.

side was dark blue, which indicates the combustion of fuel lean mixture. Conversely, the flame luminosity was brighter at the $\mathrm{N}$ side. There was also a gap between the flame and combustor wall. The gap between the flame and combustor wall was wider at the $\mathrm{N}$ side than the gap at the $\mathrm{M}$ side. Based on the flame visualization with different equivalence ratios, it was predicted that reactant at the $\mathrm{N}$ side was fuel rich mixture. An investigation by placing an external heater under the combustor shows that size of the gap without flame at the $\mathrm{M}$ side was decreased, and the flame was closer to the wall. On the contrary, size of the gap without flame at the $\mathrm{N}$ side was increased and the flame luminosity was brighter. These results indicate that the gap at the $\mathrm{M}$ side was caused by the wall cooling or thermal quenching that led to the flame extinguishing around the wall. In this paper, this gap was called quenching gap due to the heat loss. Meanwhile the gap at the $\mathrm{N}$ side did not relate to wall cooling or thermal quenching. Based on the flame color and luminosity, it is supposed that the $\mathrm{N}$ side was an area of fuel rich mixture. There is nonhomogeneous fuel-air mixture; the closer the observed point to the $\mathrm{N}$ side the higher the fuel concentration, even higher than the flammability limit. Hence, the combustion reaction could not occur at the $\mathrm{N}$ side. The external heating leads to faster fuel evaporation and 


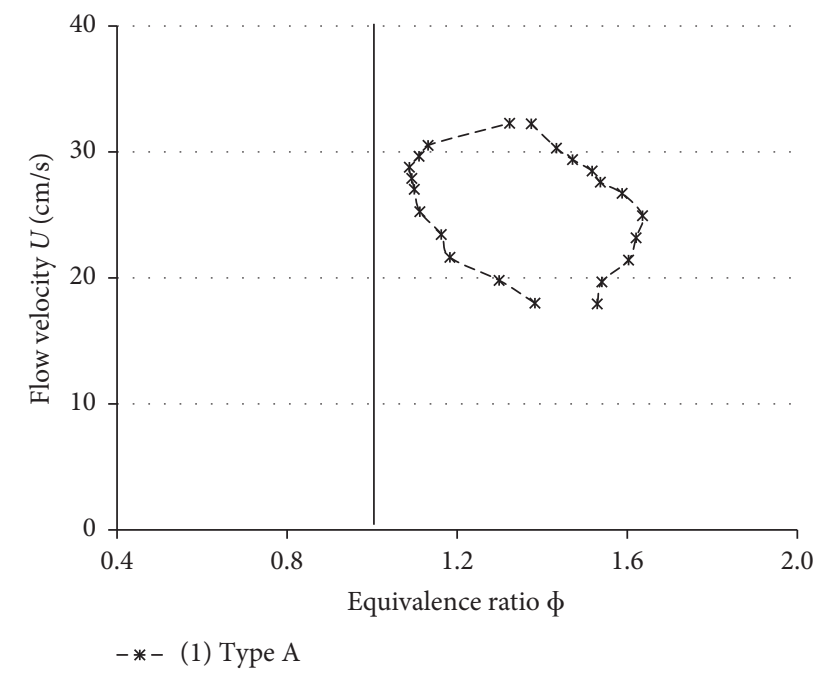

Figure 7: Flame stability inside mesocombustor type A.

higher fuel concentration at the $\mathrm{N}$ side. The distance between flame and combustor wall is called out-of-flammability limit gap.

The flame visualization inside combustor type A showed that fuel vapor was not evenly distributed on the combustor cross section and induced nonhomogeneous air-fuel mixture. Figure 6 shows that the fuel flows from the narrow canal inside mesocombustor wall into the circular canal in the $M$ side and thereafter flows to up and down direction around the combustor and enters into the combustor through five small holes on the circular canal. Eventually, these two streams merge again at the $\mathrm{N}$ side. Because the fuel inlet hole located in the circular canal has smaller diameter $(d=0.5 \mathrm{~mm})$ than circular canal wide, the fuel and its vapor tend to flow into the $\mathrm{N}$ side. Therefore, only a little amount of fuel enters the combustion chamber through holes a and b. At the meeting point of fuel stream at the $\mathrm{N}$ side, flow velocity was decreased and converted into pressure, resulting in high pressure area around $\mathrm{N}$ side. This high pressure involves high fuel velocity flow into the combustion chamber through hole $d$. It is supposed that fuel velocity at the holes $\mathrm{c}$ and $\mathrm{e}$ was larger than that one of holes a and b but smaller than fuel velocity at the hole d. On the other side, air flowed from the axial direction. Hereafter, air and fuel vapor mixed inside the combustion chamber. Nonuniform fuel vapor flow from each fuel inlet hole leads to nonuniform equivalence ratio distribution inside the combustor. The reactant flowing at the $\mathrm{M}$ side was a lean mixture; fuel concentration gradually increases toward $\mathrm{N}$ side and achieves the largest equivalence ratio at the $\mathrm{N}$ side. This phenomenon involves nonhomogeneous flame color and asymmetry flame location on the combustor cross section.

Figure 7 indicates the stability of hexane combustion inside the mesocombustor type $\mathrm{A}$. The equivalence ratio in this graphic represents the equivalence ratio average calculated based on the fuel and air quantity injected into the combustion chamber. This figure shows that the stable combustion could establish only at equivalence ratio larger than unity $(\phi>1)$. Meanwhile, flame is stable at $1<\phi<1$ in a general case of combustion. This is because the calculation of the equivalence ratio becomes overpredicted which is related to unburned fuel on the $\mathrm{N}$ side that is included in the equivalence ratio calculation. Thus, in the actual condition there exists stable combustion with equivalence ratio around unity, even $\phi<1$, especially at M side area. Conversely, there exists a region with a very high equivalence ratio around $\mathrm{N}$ side, beyond its flammability limit, which results in unburned fuel. These conditions result in an energy loss and pollution, which is should be avoided in micropower generator application. The desired combustion in the micro/mesoscale combustor is a stable combustion at high reactant velocity with an equivalence ratio around unity or less than unity $[4,9,14]$.

To improve the fuel vapor distribution inside the mesocombustor, the narrow canal was expanded to be an annulus canal surrounding the combustor wall. This annulus canal has five holes at the upstream side as entrance holes for the fuel vapor as denoted in Figure 2. This combustor is called combustor type B. More uniform fuel vapor flow rate at each entrance hole is expected by using this mesocombustor configuration, so that more homogeneous fuel vapor-air mixture is produced in the combustion chamber. This would surely generate a better combustion. Figure 8 illustrates the flame visualization inside the mesocombustor type $\mathrm{B}$ at reactant velocity of $20 \mathrm{~cm} / \mathrm{s}$ and equivalence ratio of $\phi=1.0$ and $\phi=1.1$.

The most important result from combustor type $B$ is a fact that flame could be established at equivalence ratio equal to unity as indicated at Figure 8 , or even less than unity. This figure shows that combustor type B has better flame visualization than combustor type A; that is, flame area was wider and relatively had symmetrical flame position, as well as indicating more uniform color. The flame shape was circle, nearly filling the combustor cross section, especially at lower equivalence ratio, $\phi=1$. Flame color was almost uniform, except near fuel injection point on the annulus canal (point $\mathrm{O}$ ). There existed a little area with brighter flame luminosity, which indicates an area with higher fuel vapor content. Nevertheless, at higher reactant equivalence ratio the flame position slightly shifted away from the $\mathrm{P}$ side. The flame visualization and flame shifting mechanism will be discussed at the next section.

To facilitate indication of a definite position, the marks $\mathrm{O}, \mathrm{P}$, and $\mathrm{Q}$ were added on the flame picture (Figure 9). The liquid fuel was injected into annulus canal at the point $\mathrm{O}$; then the fuel flowed to the bottom of the combustor; after that fuel flowed to the upstream direction while evaporating inside the canal. Evaporated fuel moves up surrounding the combustion chamber. Hence, annulus canal at the O-P side and lower side contained more fuel and fuel vapor, resulting in more fuel vapor flow from holes a and e, so that fuel rich mixture existed around $\mathrm{O}-\mathrm{P}$ side and flame in this region has brighter luminosity. The flame at the O-P side and lower side was brighter than that one at another area, which indicates that air-fuel vapor mixture at O-P side has more fuel vapor content.

Mesocombustor type B had an annulus canal and had wider contact surface between the fuel and combustor wall 


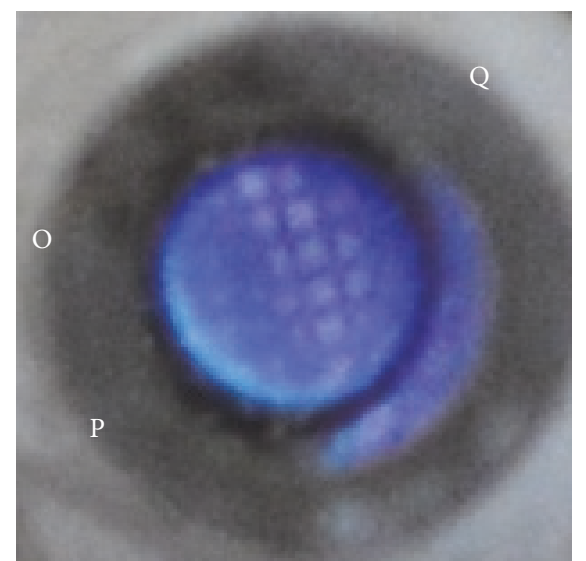

$\phi=1.0$

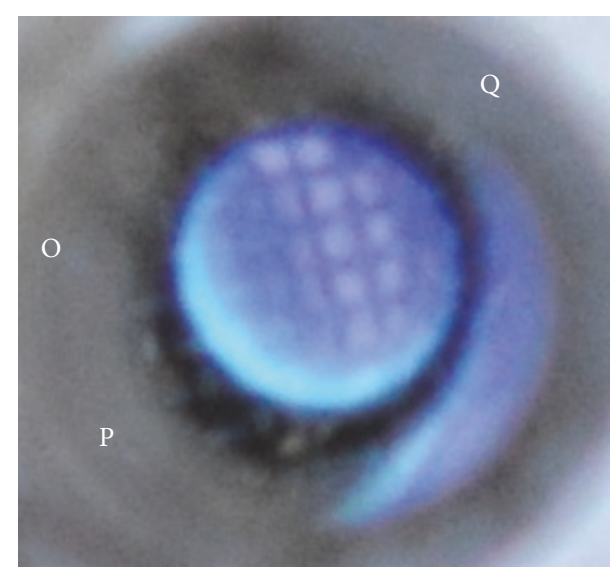

$\phi=1.1$

FIgURE 8: Flame visualization inside mesocombustor type B.

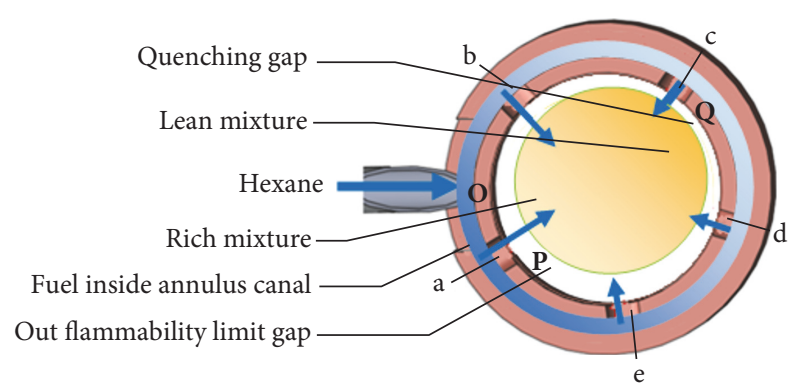

FIgURE 9: The flow of fuel and flame in mesocombustor type B.

than type A, so that the heat transfer from the combustor wall was higher than that one at type A. Thus, mesocombustor type B was able to evaporate liquid fuel better than the type A. The fuel can flow to fulfill entire space around the combustion chamber since entering the annular canal and evaporating. In case the fuel evaporated completely inside the annulus canal and fulfills the canal, fuel vapor flows into the combustion chamber through each small hole at the same velocity. All fuel vapor diffuses into air flow to generate relatively homogeneous mixture. Combustion of this mixture results in relatively uniform flame color that fills up the combustor cross section as the case of mixture with equivalence ratio $\phi \leq 1$. Nevertheless, higher fuel flow caused the annulus to be filled up with liquid fuel and cool both wall and flame, which subsequently put out the flame. Stable flame could be established inside combustor type B only at $0.85<\phi<1.2$. Upper limit of stable area shifts to smaller equivalence ratio, resulting narrower area of flame stability, as illustrated in Figure 10.

All of the combustor types have copper section surrounding the flame, intended to absorb the heat of flame. This section is continued with copper section to evaporate liquid fuel inside a canal in combustor wall. Heat transfer occurred from the flame which has temperature around $1000^{\circ} \mathrm{C}$ or higher to the copper tube by convection. Then, heat

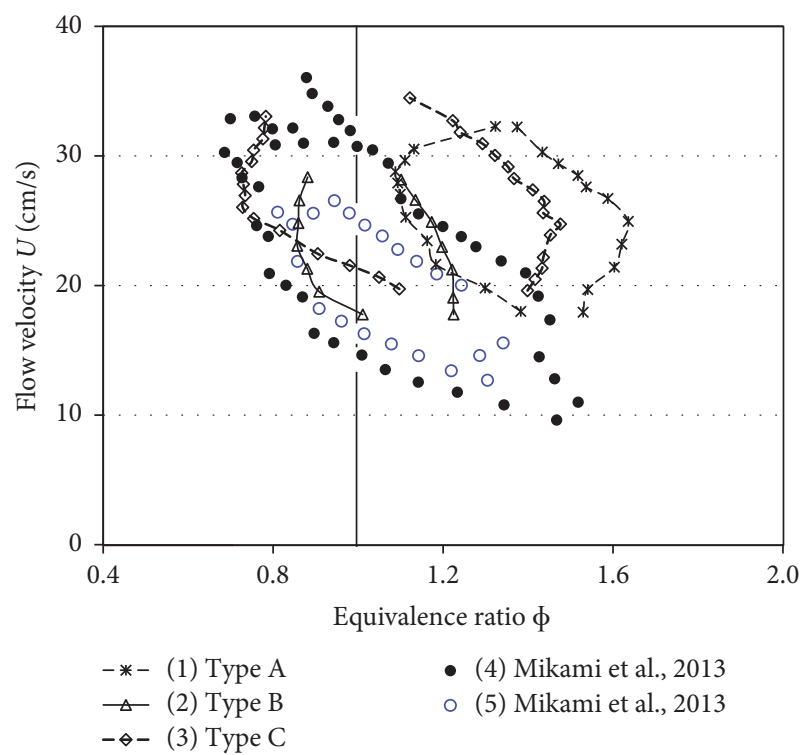

FIgUre 10: Flame stability limits inside type A, type B, and type C mesocombustor.

is conducted to upstream direction through copper section to heat up and evaporate the fuel. The copper section is covered by ceramic bond which has low thermal conductivity as insulation, to suppress heat loss to the environment and improve the heating and evaporation of liquid fuel. High temperature combustor wall, low velocity hexane, and thin film formation on the combustor wall, as well as low boiling temperature of hexane $\left(69^{\circ} \mathrm{C}\right)$, cause the liquid fuel to evaporate inside the annulus canal. This prediction is confirmed by visual observation on the fuel vaporization at the surface of stainless steel wire mesh inserted inside quartz glass tube mesocombustor at the same fuel flow rate [13]. Fuel evaporated completely at the stainless steel wire mesh surface, which theoretically had lower temperature than copper annulus canal. 


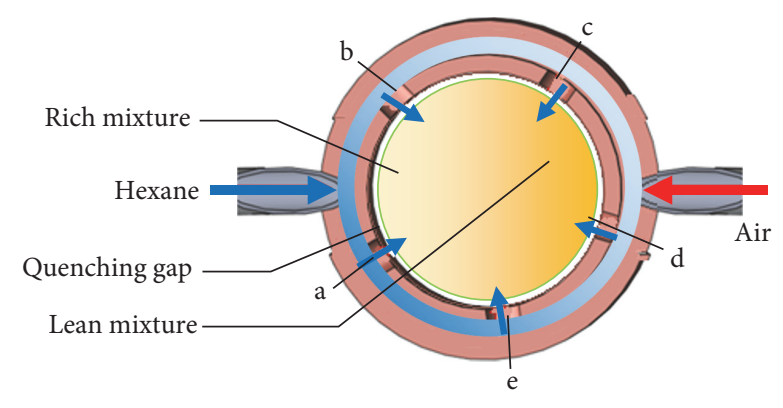

FIGURE 11: The flow of fuel and flame in mesocombustor type C.

Inside type B mesocombustor, the liquid fuel is injected near the flame and causes flame cooling directly, thus disrupting flame stability. The limit flame stability curve becomes narrower than type $\mathrm{A}$. This can be understood because the annulus canal inside type B combustor accommodates more liquid fuel than type A. Improvement to the type $\mathrm{C}$ mesocombustor is placement of the liquid fuel inlet at the upstream side of the combustor. This will allow the occurrence of liquid fuel heating and evaporating while avoiding excessive flame cooling. Both of fuel and air inlet are placed on the annulus, improving the liquid film formation as well as its evaporation. Furthermore, fuel vapor and air have mixed before entrance to the combustion chamber through small holes around the combustion chamber. The occurrence of flame and the absence of liquid phase in the combustion chamber prove that evaporation has taken place.

Different from type A and type B, where the air was inserted into combustion chamber from the main channel while the fuel was from the wall, in type $C$, the air and fuel were injected simultaneously to the annulus canal. Mesocombustor type $\mathrm{C}$ is illustrated in Figure 3.

The process of mesocombustor type $C$ is illustrated in Figure 11. The position of reactant input and flame visualization is illustrated in Figure 12. In operational situation during the flame, fuel (n-hexane) was injected into the annulus canal, and the thin layer of film liquid was shaped. This layer received extra heat from the wall and then evaporated and expanded in the annulus canal. The air was also injected into the annulus canal, so that it could be mixed with the fuel vapor to ease the evaporation and to produce premix fuel. The mixture of this fuel vapor then flowed through the smooth holes of a, b, c, d, and e into the main combustion area of mesocombustor from the radial headed downstream through the mesh and then burned.

Flame visualization was carried out at the flow velocity of $28 \mathrm{~cm} / \mathrm{s}$, as illustrated in Figure 12. The liquid fuel was inserted into the annulus canal on one side and air on the other side. The flame section was perfectly concentric circle. At low $\phi \quad(\phi=0.7)$ or at the condition of lean mixture, the flame color was dominated by dark blue while at high $\phi \quad(\phi=$ 1.3) or rich mixture condition, the flame color was dominated by bright colors. To ease the readers' observation, in Figure 12 it was given the mark of $\mathrm{R}$ and $\mathrm{S}$. At the flame circle, the bright and dark color distribution were visible to the observant. The bright color was visible at the side of fuel input below
R. The difference on the bright and dark color was more evident at high $\phi \quad(\phi=1.3)$. At $\phi=0.7$ a thin gap without flame around the flame circle was clearly visible, which was caused by the cooling wall. The gap without flame would get thicker with the rise of $\phi$ up to the stoichiometry condition $(\phi=1)$, yet the flame circle would remain concentric in the mesocombustor section. Subsequently, higher $\phi$ caused the higher fuel concentration input, higher fuel trickled below (R) inside the annulus canal. A higher heat was required for evaporation, which finally cooled the combustor wall in the side $\mathrm{R}$. The wall cooling in the side $\mathrm{R}$ caused the sticking of combustion reaction around the area and was read as the gap thickening without flame around R. Subsequently, the flame shifted to S, as illustrated in Figure 12.

The relationship curve between temperature and equivalent ratio is illustrated in Figure 13. At low $\phi$ up to the condition a bit over stoichiometry, the total of combusted heat was still minimal and caused low temperature level $\left(975^{\circ} \mathrm{C}\right)$. Subsequently, as the increasing level of fuel or of $\phi$, the combusted fuel energy would correspondingly increase and thereby caused the increasing temperature. After the equivalent ratio of $\phi=1.1$ or the highest temperature $\left(1150^{\circ}\right)$, the increasing fuel or the increasing $\phi$ caused the cooling flame until it was put out at $\phi=1.3$ and temperature around $1000^{\circ} \mathrm{C}$. After reaching top condition $(\phi=1.1)$ of fuel flow adding, the temperature decreased and the gap without flame thickened.

Figure 10 illustrated the curve of flammability limit in (1) type A mesocombustor, (2) type B mesocombustor, (3) type $\mathrm{C}$ mesocombustor, (4) single mesh mesocombustors, and (5) double mesh mesocombustors. Mesoscale combustor numbers (4) and (5) were those in previous researches referred to in this research. Both were made of quartz tube $3.5 \mathrm{~mm}$ with mesh insertion employing the electrospray for the atomization of liquid fuel [9]. Mesocombustor number (4) employed a single mesh insertion which functioned as a droplet collector as well as a flame holder. The flame stability of mesocombustor number (4) occurred at the equivalent ratio of $\phi$ around 0.8 to 1.3 , in which high $\phi$ caused the wall wetting and flame cooling which caused flame extinguishing. Such condition was successfully corrected by mesocombustor number (5) which employed double mesh insertion in which the first mesh functioned as droplet collector and the second mesh as flame holder. The flame stability of mesocombustor number (5) at the equivalent ratio of $\phi$ around 0.7 to 1.5 was proven to be wider than number (4). An effort to maximize recirculating the heat was by employing the insertion of copper tube section with narrow canal, which was the mesocombustor type A as illustrated in Figure 10, number (1). The flame could be stabilized in equivalent ratio of $\phi$ $=1.1$ to $\phi=1.6$, which was significantly high, considering the situation above was within stoichiometry condition. As previously stated, this condition occurred due to the gap without flame or the nil combustion reaction triggered by the rich mixture causing the out-of-stability flame. The expansion of annulus canal to shift the flame stability was at the condition of $\phi=0,8$ to $\phi=1.2$, lower than mesocombustor type A. However, the annulus canal caused fuel accumulation in the canal leading to both wall and flame cooling, which 


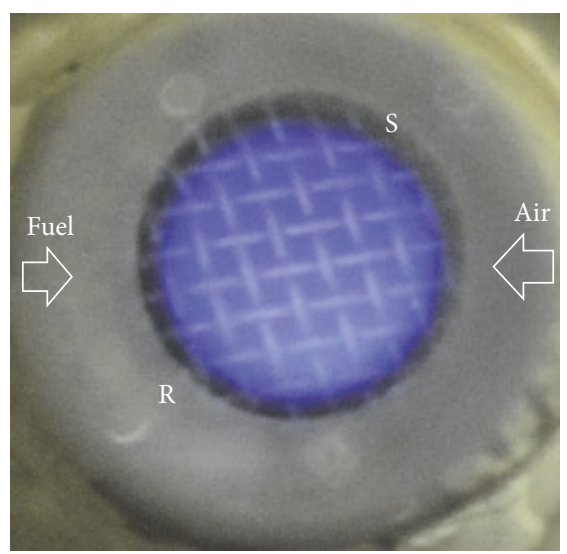

$\phi=0.7$

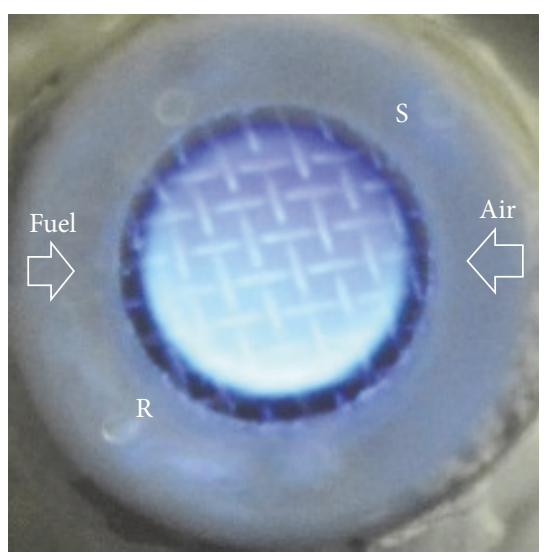

$\phi=1$

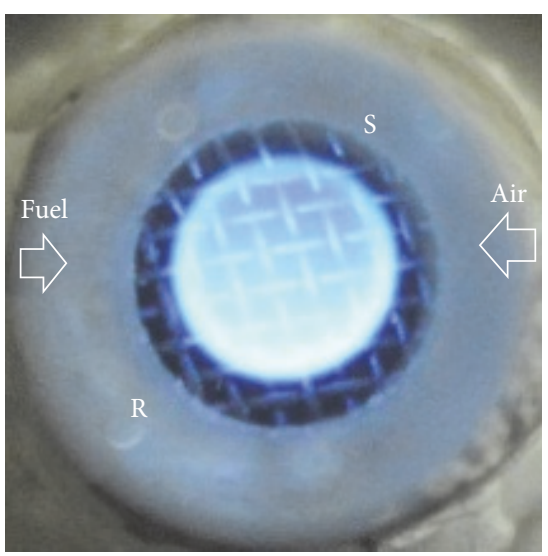

$\phi=1.3$

FIGURE 12: Flame visualization in mesocombustor type $\mathrm{C}$ with film evaporation.

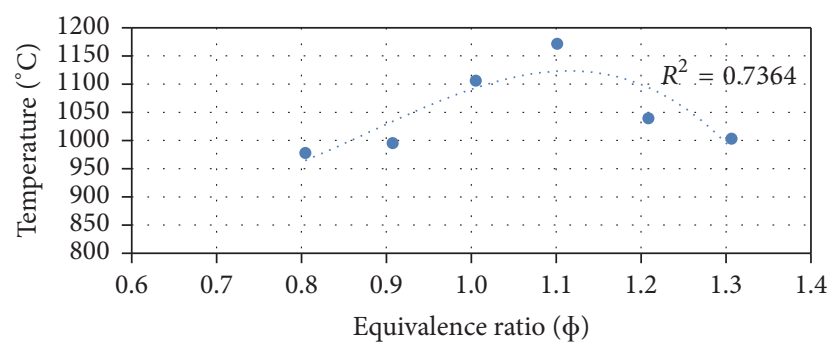

FIGURE 13: Graphic of temperature versus varied equivalent ratios at flow velocity $28 \mathrm{~cm} / \mathrm{s}$.

finally led to the flame extinguishing. The flame stability area would be narrower than type A. The mesocombustor type C used copper section with annulus canal inside the wall where the air was flowed into and mixed with liquid fuel. The flame stability area of mesocombustor type $\mathrm{C}$ was around $\phi=0.73$ to $\phi=1.48$ in stoichiometry condition. The flame stability area of mesocombustor type $\mathrm{C}$ was wider than those in type $A$ and type $B$ and even wider than mesocombustor number (4) that employed single mesh-electrospray. Compared to number (5), the flammability limits in mesocombustor type $\mathrm{C}$ are not significantly narrower. The flammability limit in mesocombustor type $\mathrm{C}$ was still not significantly narrower than those in mesocombustor number (5).

\section{Conclusion}

Experimental research on hexane liquid fuel combustion in quartz-tube mesocombustor $3.5 \mathrm{~mm}$ by inserting copper section for heat recirculation has been conducted. There were three types of mesocombustor based on the copper section insertion. The flame on three mesocombustors could be stabilized without catalyst and also external heater. In mesocombustor type A, in which fuel was flowed into narrow canal inside the copper wall, the flame could be stabilized only at high equivalent ratio $(\phi=1.1$ to $\phi=1.6)$. This was due to the presence of gap without flame reaction since the gap area was filled up by significantly rich mixture exceeding the flame stability limits. The expansion of narrow canal into annulus shape, as employed in mesocombustor type B, was able to shift the flame stability from $\phi=0,8$ to $\phi=1.2$ but still followed by the narrowing of flame stability gap due to the wall cooling. The last one was mesocombustor type $\mathrm{C}$, in which both fuel and air were flowed into the annulus canal inside the copper section wall. Through this process, the fuel evaporation and fuel-air mixing could perfectly be done. The flame could be stabilized within the range of $\phi=0.73$ and $\phi=1.48$, which was wider than those in type A, type $\mathrm{B}$, and even in the mesocombustor employing electrospray with single mesh. The flame's shape was perfectly concentric circle filling up the mesocombustor's section. At $(\phi=0.7)$, a thin gap without flame around the flame circle was visible as a result of the wall cooling. This gap without flame was getting thicker as the $\phi$ raised up, yet the flame circle would remain concentric, up to stoichiometry condition of $\phi=1$. As the rise of $\phi$, the gap thickening without flame at one side occurred, which was at the side where the fuel trickled downward. This indicated that the cooling at the side was more significant than others.

\section{Conflicts of Interest}

The authors declare that there are no conflicts of interest regarding the publication of this paper.

\section{Acknowledgments}

The authors acknowledge Directorate General Higher Education, the Ministry of Research, Technology and Higher Education of Indonesia, that has funded the research and also sponsored doctoral program study of first author.

\section{References}

[1] W. M. Yang, D. Y. Jiang, S. K. Chou, K. J. Chua, K. Karthikeyan, and H. An, "Experimental study on micro modular combustor for micro-thermophotovoltaic system application," International Journal of Hydrogen Energy, vol. 37, pp. 9576-9583, 2012.

[2] V. Vijayan and A. K. Gupta, "Thermal performance of a mesoscale liquid-fuel combustor," Applied Energy, vol. 88, pp. 23352343, 2011. 
[3] S. Yuasa, K. Oshimi, H. Nose, and Y. Tennichi, "Concept and combustion characteristics of ultra-micro combustors with premixed flame," in Proceedings of the 30th International Symposium on Combustion, pp. 2455-2462, 2005.

[4] F. A. Munir, N. H, T. Seo, and M. Mikami, "Improvement Of Combustion Stability In Narrow Tubes With Wire Mesh," in Proceedings of the 24th International Symposium on Transport Phenomena, Yamaguchi, Japan, November 2013.

[5] W. M. Yang, S. K. Chou, C. Shu, Z. W. Li, and H. Xue, "Combustion in micro-cylindrical combustors with and without a backward facing step," Applied Thermal Engineering, vol. 22, no. 16, pp. 1777-1787, 2002.

[6] N. Kim, S. Kato, T. Kataoka et al., "Flame stabilization and emission of small Swiss-roll combustors as heaters," Combustion and Flame, vol. 141, pp. 229-240, 2005.

[7] K. Bijjula and D. G. Vlachos, "Catalytic ignition and autothermal combustion of JP-8 and its surrogates over a $\mathrm{Pt} / \gamma$-Al2O 3 catalyst," in Proceedings of the Combustion Institute, vol. 33, pp. 1801-1807, 2011.

[8] A. Yamamoto, H. Oshibe, H. Nakamura, T. Tezuka, S. Hasegawa, and K. Maruta, "Stabilized three-stage oxidation of gaseous $\mathrm{n}$-heptane/air mixture in a micro flow reactor with a controlled temperature profile," in Proceedings of the Combustion Institute, vol. 33, pp. 3259-3266, 2011.

[9] M. Mikami, Y. Maeda, K. Matsui, T. Seo, and L. Yuliati, “Combustion of gaseous and liquid fuels in meso-scale tubes with wire mesh," in Proceedings of the Combustion Institute, vol. 34, pp. 3387-3394, 2013.

[10] C. D. Sebastian Kaiser, Kyritsis, Dobrowolsky Peter, B. L. Marshall, and A. Gomez, "The electrospray and combustion at the mesoscale," Journal of the Mass Spectrometry Society of Japan (JMSSJ), vol. 51, pp. 42-49, 2003.

[11] V. Shirsat and A. K. Gupta, "Performance characteristics of methanol and kerosene fuelled meso-scale heat-recirculating combustors," Applied Energy, vol. 88, pp. 5069-5082, 2011.

[12] L. Yuliati, N. Kojima, and M. Mikami, "Electrospray characteristics of ethanol," in Proceeding The 13th Annual Conference on Liquid Atomization and Spray Systems- Asia, Wuxi, China, October, 2009.

[13] L. Yuliati, T. Seo, and M. Mikami, "Brief communications Liquid-fuel combustion in a narrow tube using an electrospray technique," Combustion and Flam, vol. 159, pp. 462-464, 2012.

[14] U. W. Taywade, A. A. Deshpande, and S. Kumar, "Thermal performance of a micro combustor with heat recirculation," Fuel Processing Technology, vol. 109, pp. 179-188, 2013. 


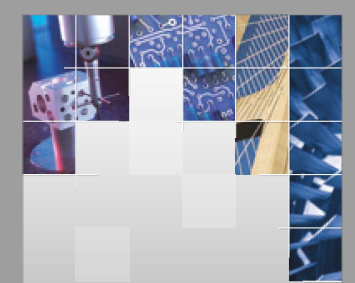

\section{Enfincering}
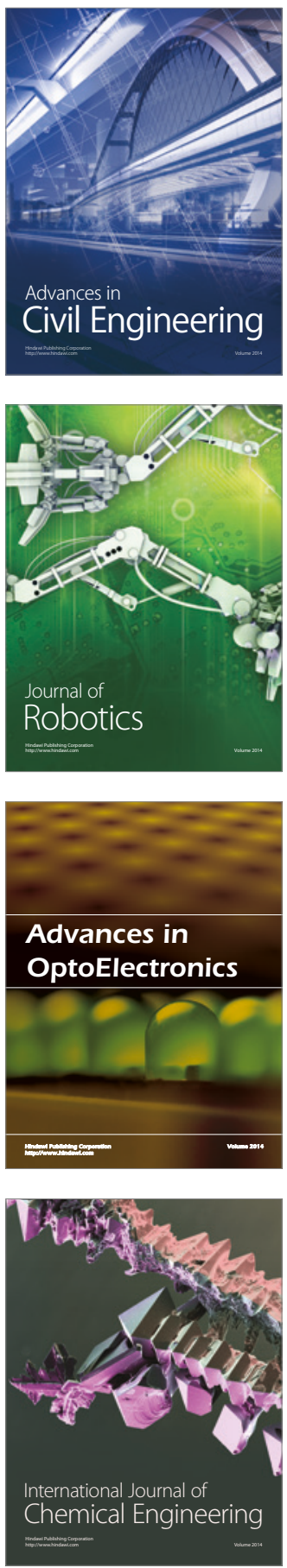

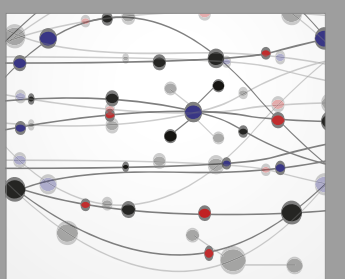

The Scientific World Journal

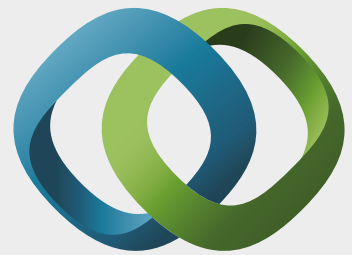

\section{Hindawi}

Submit your manuscripts at

https://www.hindawi.com
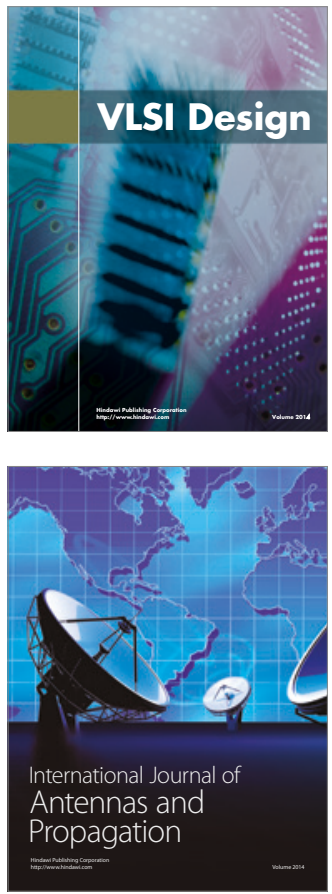

\section{Rotating}

Machinery
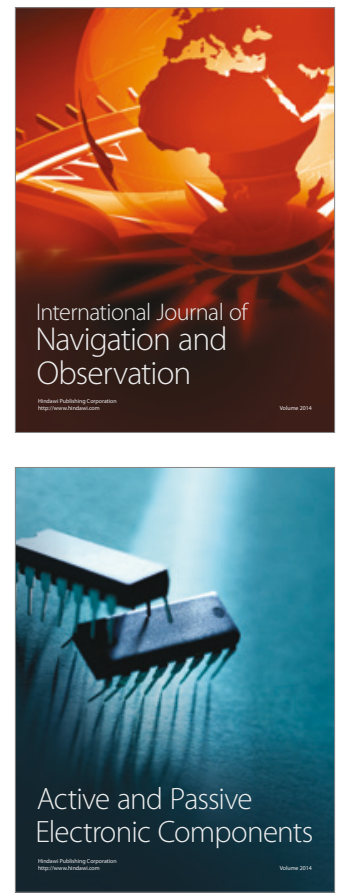
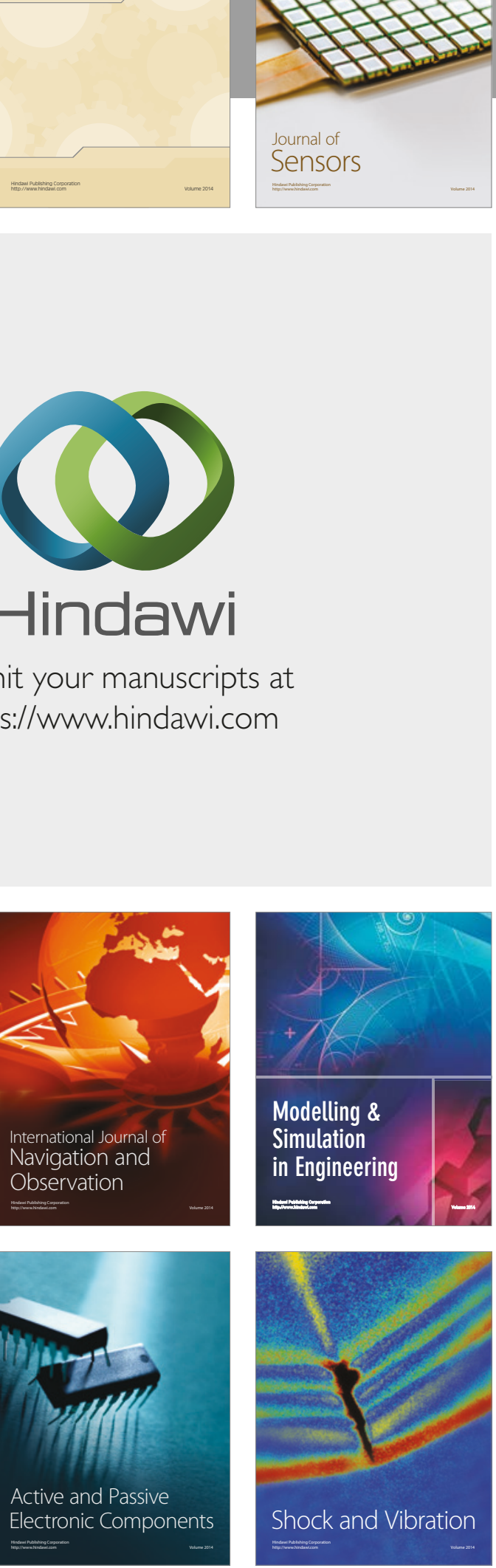
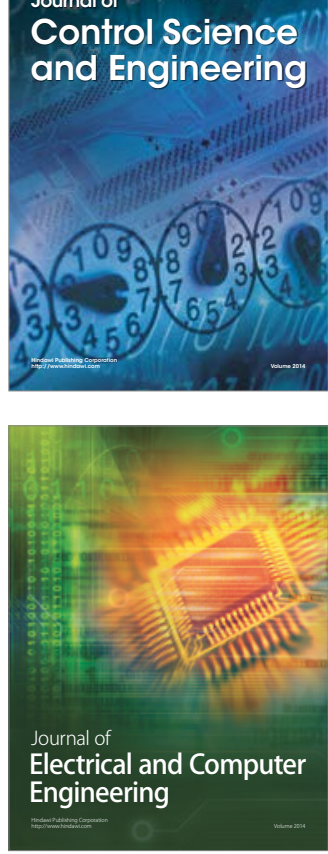

Distributed

Journal of

Control Science

and Engineering
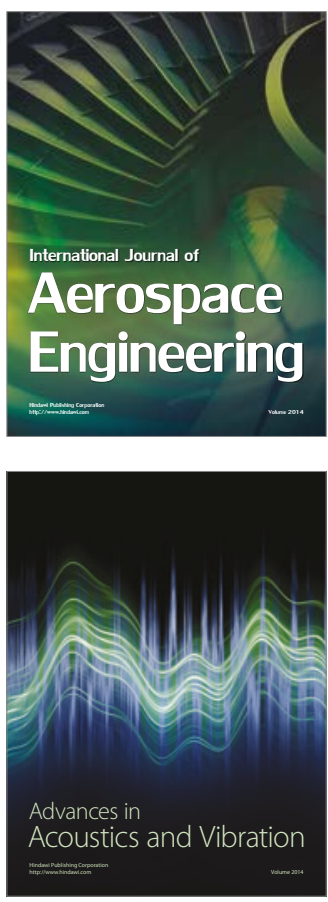

Sensor Networks 